\title{
THE
}

\section{Vertical Profiles, Sources and Transport of PFASs in the Arctic Ocean}

Leo W. Y. Yeung

Clifton Dassuncao

Scott Mabury

Elsie M. Sunderland

Xianming Zhang

See next page for additional authors

The University of Rhode Island Faculty have made this article openly available.

Please let us know how Open Access to this research benefits you.

This is a pre-publication author manuscript of the final, published article.

Terms of Use

This article is made available under the terms and conditions applicable towards Open Access

Policy Articles, as set forth in our Terms of Use.

\section{Citation/Publisher Attribution}

Leo W.Y. Yeung, Scott Mabury, Clifton Dassuncao, Xianming Zhang, Elsie M. Sunderland, Rainer Lohmann. Vertical Profiles, Sources and Transport of PFASs in the Arctic Ocean. Environ Sci Technol 2017, 51, 6735-6744.

Available at: http://dx.doi.org/10.1021/acs.est.7b00788.

This Article is brought to you for free and open access by the Graduate School of Oceanography at DigitalCommons@URI. It has been accepted for inclusion in Graduate School of Oceanography Faculty Publications by an authorized administrator of DigitalCommons@URI. For more information, please contact digitalcommons-group@uri.edu. 


\section{Authors}

Leo W. Y. Yeung, Clifton Dassuncao, Scott Mabury, Elsie M. Sunderland, Xianming Zhang, and Rainer Lohmann

This article is available at DigitalCommons@URI: https://digitalcommons.uri.edu/gsofacpubs/174 
2 Leo W.Y. Yeung, ${ }^{1,2 *}$ Clifton Dassuncao, ${ }^{3}$ Scott Mabury, ${ }^{1}$ Elsie M. Sunderland, ${ }^{3}$ Xianming

${ }^{1}$ Department of Chemistry, University of Toronto, Toronto, Ontario M5S 3H6, Canada ${ }^{2}$ School of Science and Technology, Orebro University, 70182 Örebro, Sweden

${ }^{3}$ Harvard John A. Paulson School of Engineering and Applied Sciences, Harvard University,

${ }^{4}$ Graduate School of Oceanography, University of Rhode Island, Narragansett, RI 02882, 
37

\section{Abstract}

The relative importance of atmospheric versus oceanic transport for poly- and perfluorinated alkyl substances (PFASs) reaching the Arctic Ocean is not well understood. Vertical profiles from the Central Arctic Ocean and shelf water, snow and meltwater samples were collected in 2012; 13 PFASs (C6-C12 PFCAs; C6, 8, 10 PFSAs; MeFOSAA and EtFOSAA, and FOSA) were routinely detected (range: $<5-343 \mathrm{pg} / \mathrm{L}$ ). PFASs were only detectable above $150 \mathrm{~m}$ depth in the polar mixed layer (PML) and halocline. Enhanced concentrations were observed in snow and meltpond samples, implying atmospheric deposition as an important source of PFASs. Model results suggested atmospheric inputs to account for 34-59\% ( 11-19 pg/L) of measured PFOA concentrations in the PML (mean $32 \pm 15 \mathrm{pg} / \mathrm{L}$ ). Modeled surface and halocline measurements for PFOS based on North Atlantic inflow (11-36 pg/L) agreed with measurements (mean, 17, range $<5-41 \mathrm{pg} / \mathrm{L}$ ). Modeled deep water concentrations below 200 m $(5-15 \mathrm{pg} / \mathrm{L})$ were slightly higher than measurements $(<5 \mathrm{pg} / \mathrm{L})$, suggesting the lower bound of PFAS emissions estimates from wastewater and rivers may provide the best estimate of inputs to the Arctic. Despite low concentrations in deep water, this reservoir is expected to contain most of the PFOS mass in the Arctic (63-180 Mg) and projected to continue increasing to 2038 .

\section{TOC art}

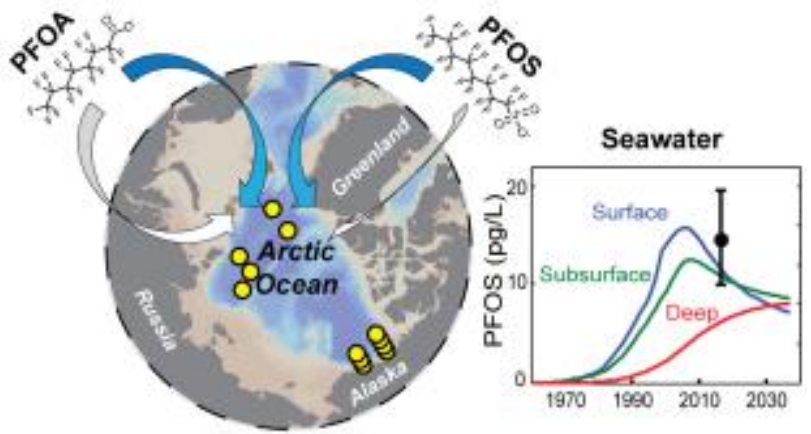




\section{Introduction}

Perfluoroalkyl and polyfluoroalkyl substances (PFASs) are groups of anthropogenic chemicals having a perfluoroalkyl moiety $\left(\mathrm{C}_{n} \mathrm{~F}_{2 n+1}-\right)$ with different polar heads (e.g., carboxylate, sulfonate, phosphonate). ${ }^{1}$ Much attention has been given to two perfluoroalkyl acids (PFAAs) - perfluorooctane sulfonate (PFOS) and perfluorooctanoate (PFOA) because of their potential toxic and bioaccumulative effects, as well as their ubiquitous occurrence in the environment including remote areas. ${ }^{2-10}$ In May 2009, PFOS and chemicals that can degrade to PFOS were listed in the Stockholm Convention as Persistent Organic Pollutants, and parties to the Convention must seek to eliminate the production and use of PFOS. ${ }^{11}$

Since PFAAs are strong acids and highly soluble in water, oceans are believed to be the final global sink for these compounds. ${ }^{12}$ Atmospheric transport of volatile fluorotelomer alcohols (FTOHs) and subsequent oxidative reactions of these compounds are also sources of PFAAs in remote areas like the Arctic, as evidenced by the detection of the FTOHs and their intermediates in remote areas. ${ }^{13-16}$ Inputs of surface waters from the North Pacific and North Atlantic and atmospheric deposition all lead to accumulation of PFASs in Arctic surface waters. The majority of seawater inflow to the Arctic occurs from mid-depth North Atlantic seawater (20-200 m) and results in PFASs being present below the polar mixed layer (PML). ${ }^{10,12}$

Several previous studies have reported PFAA concentrations in surface water in different oceans. ${ }^{3,17-21}$ Relatively higher concentrations were found in the Atlantic (PFOS: $<5$ 291 pg/L; PFOA: <4-439 pg/L) compared to the Pacific (PFOS: <5-78 pg/L; PFOA: <4-142 $\mathrm{pg} / \mathrm{L}) ;{ }^{3,20}$ and higher concentrations were observed in coastal regions compared to off-shore areas. ${ }^{6,22}$ Previous PFAS measurements in Arctic seawater have been limited to surface water (<20 m depth). ${ }^{17-19,21}$ The composition of PFASs previously measured in surface waters 
varied across different locations, likely due to their complex sources and transport pathways in the Arctic. ${ }^{19}$

Compared to the major ocean basins, the Arctic Ocean is smaller and has a much greater continental shelf area $(70 \%)$ and freshwater inputs. ${ }^{23}$ It provides an oceanic pathway between the Pacific and the Atlantic basins and plays an important role in the global thermohaline circulation through its role in the Atlantic Meridional Overturning Circulation. ${ }^{23}$ Water of Atlantic origin enters the Arctic through the east side of the Fram Strait into the Eurasian Basin or the Barents Sea (Figure 1). Water flows in a counter-clockwise direction in the Nansen basin and then either to the Amundsen basin, or to the Makarov or Canada basins. A minor influx of Pacific water enters the Canada Basin through the Bering Strait (Figure 1). Seasonally varying fresh water input also contributes to Arctic surface waters and are thought to be important for inputs of other contaminants. ${ }^{24-26}$ The outflows of the Arctic Ocean are all to the Atlantic through either the western side of the Fram Strait ${ }^{24}$ or the complex channels of the Canadian Archipelago. ${ }^{27}$

The entire Arctic Ocean is seasonally covered by ice. ${ }^{28}$ Both the formation (reduced wind-mixing) and melting of sea-ice (fresher surface layer) contribute towards ocean stratification. Complex surface and subsurface dynamics of the Arctic water column mean surface water PFAS measurements are not sufficient for understanding spatial and temporal variability and mass accumulation. In addition, biological exposures extend beyond the surface mixed layer for benthic and demersal food webs.

While information on PFASs in the Arctic is limited to surface waters, several studies show the penetration of other organic contaminants to deeper waters. Sobek and Gustafsson ${ }^{29}$ demonstrated that concentrations of polychlorinated biphenyls (PCBs) were greatest in the intermediate and deep water in samples collected in the early 2000s. A similar enrichment in deeper waters was also confirmed for polybrominated diphenylethers (PBDEs) in the central 
Arctic Ocean. ${ }^{30}$ Previous work had already shown that the presence of hexachlorocyclohexanes (HCHs) in deeper waters caused their export from the Arctic Ocean. ${ }^{31}$ Additional vertical profiles were reported for PCBs and PBDEs for the North Atlantic, confirming their penetration to below $2000 \mathrm{~m} .{ }^{32}$ Yamashita et al. ${ }^{22}$ also showed detectable concentrations of several PFASs in the Subarctic Labrador Sea region at depths greater than $3500 \mathrm{~m}$ in vertical profiles from 2004. For these profiles, surface water PFAS concentrations were enriched relative to subsurface waters. The available evidence for these organic contaminants implies that persistent compounds are present in deep waters at concentrations that may exceed those measured in the surface water. A recent study has shown accumulation of PCBs and PBDEs in deep-sea organisms. ${ }^{33}$

In the present investigation, water samples were collected and analyzed from different depths of the water column at eight locations in the central Arctic (seawater, snow and meltpond water), and seven stations on the Arctic shelf (Figure 1). The aims of this study were to: (i) understand the spatial and vertical patterns of PFASs in Arctic Ocean seawater; (ii) assess the roles of atmospheric and oceanic transport of PFASs into the Arctic Ocean; and (iii) reconcile measured PFAS data with modeled results for different Arctic ocean water masses based on a geochemical Arctic Ocean box model.

\section{Materials and Method}

Details of analytical standards and reagents used in the present study are given in the Supporting Information (SI).

Sample collection. Sampling locations are shown in Figure 1. Coordinates and further details of sample collection, including temperature and salinity data for all cruises are provided in SI Tables S1 and Figure S1. 
Water samples (1L/layer of water/location) were collected on two separate cruises in 2012 as follows: (1) four locations during expedition ARK-XXII/3 in the Central Arctic from surface to bottom (up to $4220 \mathrm{~m}$ ) by the research icebreaker Polarstern between August and September 2012 (SI Tables S1i); and (2) seven locations on the Beaufort Chuckchi shelf from surface to bottom (up to $385 \mathrm{~m}$ ) by the United States Coast Guard icebreaker Healy in October 2012 (SI Tables S1i). Snow and melt pond water samples were also collected in four ice stations during the expedition ARK-XXII/3 (SI Table S1i). Details of the cruise reports can be found elsewhere..$^{34,35}$

Analytical standards and reagents. Potassium salts of perfluorobutane sulfonate (PFBS), PFOS and ${ }^{13} \mathrm{C}_{4}$ PFOS; sodium salts of perfluorodecane sulfonate (PFDS), perfluorohexane sulfonate (PFHxS) and ${ }^{18} \mathrm{O}_{2} \mathrm{PFHxS}$, perfluorooctanesulfonamido acetate (FOSAA; $N$-methyl and $N$-ethyl substituted: MeFOSAA, EtFOSAA), d ${ }_{3}$ MeFOSAA, d5EtFOSAA, perfluorooctanesulfonamide (FOSA), ${ }^{13} \mathrm{C}_{8}$ FOSA, perfluorohexanoate (PFHxA), ${ }^{13} \mathrm{C}_{2} \mathrm{PFHxA}$, perfluoroheptanoate (PFHpA), PFOA, ${ }^{13} \mathrm{C}_{4} \mathrm{PFOA}$, perfluorononanoate (PFNA), ${ }^{13} \mathrm{C}_{5} \mathrm{PFNA}$, perfluorodecanoate (PFDA), ${ }^{13} \mathrm{C}_{2} \mathrm{PFDA}$, perfluoroundecanoate (PFUnDA), ${ }^{13} \mathrm{C}_{2} \mathrm{PFUnDA}$, were obtained from the Wellington Laboratories (Guelph, ON).

Chemical and Instrumental analyses. Samples (seawater: $400 \mathrm{~mL}$ (duplicate), snow and meltpond water: $200 \mathrm{~mL}$ (single)) were extracted using a solid phase extraction (SPE) cartridge (Strata-X-AW cartridge, Phenomenex, Torrence, CA) following the ISO 25101 method. ${ }^{36}$ Details of the method are provided in the SI. Separation and quantification of PFASs in seawater, snow and melt pond water samples were performed using an Acquity ultra performance liquid chromatograph (UPLC) and a Xevo TQ-S tandem mass spectrometer (MS/MS - Waters Corporation) operated in negative ionization mode with an atmospheric electrospray interface. An Acquity BEH C18 column $(2.1 \times 75 \mathrm{~mm}, 1.7 \mu \mathrm{m}, 100$ A), maintained at $40{ }^{\circ} \mathrm{C}$ was used to achieve chromatographic separation. A $4 \mu \mathrm{L}$ extract 
aliquot was injected onto the column, with $2 \mathrm{mM}$ ammonium acetate in Milli-Q water and $\mathrm{MeOH}$ used as mobile phases. Detailed MS/MS conditions, including collision energies, cone voltages, and MS/MS optimization parameters have been reported elsewhere. ${ }^{37}$ Internal calibration using corresponding mass-labelled standards was used to quantify PFASs with mass-labelled standards (SI Table S2). Internal calibration curves were constructed at 5, 10, $50,100,200,500,1000,5000$, and $10000 \mathrm{pg} / \mathrm{mL}$ with the addition of an internal masslabelled standard with the final concentration of $100 \mathrm{pg} / \mathrm{mL}$. In the current investigation, target PFASs included $\mathrm{C}_{4}-\mathrm{C}_{10}$ PFSAs, $\mathrm{C}_{5}-\mathrm{C}_{14}$ PFCAs, FOSAA, MeFOSAA, EtFOSAA, and FOSA. Other PFASs including polyfluoroalkyl phosphate diesters (diPAPs: 4:2, 6:2, 6:2/8:2, 8:2/8:2, 10:2), fluorotelomer unsaturated carboxylates (FTUCAs: 6:2, 8:2, 10:2),

fluorotelomer sulfonates (FTSAs: 4:2, 6:2, 8:2), perfluorinated phosphinates (PFPiAs: 6:6, 6:8, 8:8), $N$-methyl and $N$-ethyl substituted perfluorooctanesulfonamide (MeFOSA and EtFOSA) were also monitored during LC-MS/MS analysis. The standards for the congeners of PFSA, FOSA, FOSAA, and PFOA were the linear isomer, whereas the samples were composed of both branched and linear isomers; the concentrations reported for the present study included both linear and branched isomers based on the calibration curve of the linear isomer of the standard.

Quality Assurance/Quality Control. All the reagents and apparatus (sampling bottles, transfer pipette, pipette tips and falcon tubes) were tested for the presence of target PFASs $(<0.1 \mathrm{pg} / \mathrm{mL})$. Since Milli-Q water and Waters OASIS WAX-SPE cartridges contained trace amount PFASs, polished Milli-Q water and PFOA-free extraction cartridges (Strata-X-AW cartridge, Phenomenex, Torrence, CA) were used throughout the method development and sample extraction (see the discussion in the SI). Sample extraction was performed in the Advanced Laboratory for Fluorinated and Other New Substances in the Environment (ALFONSE), at the University of Toronto at Scarborough, a Class 100 clean laboratory. Deep 
layer water samples (3000 m depth from 4 different stations) were served as field blanks and were found below limits of quantification (LOQs: 5-20 pg/L, SI Table S3). The definition of LOQs will be explained below. Matrix recoveries were confirmed using the deep layer (3000 m) of water samples $(\mathrm{n}=4)$ by spiking $100 \mu \mathrm{L}$ of the native standards $(1 \mathrm{pg} / \mu \mathrm{L})$ into spike samples and equal amount of $\mathrm{MeOH}$ into non-spike samples before extraction; mass-labelled standards were spiked into the LC vials before instrumental analysis. The recoveries were calculated by the difference between the measured valued in the spike and non-spike samples divided by the theoretical values X 100\%; most of the target PFASs had the recoveries ranged from $85-106 \%$, except $60 \%$ for FOSA (SI Table S3). The recoveries of the mass-labelled standards in the real samples $(n=69)$ based on external calibration curve were $78-121 \%$, except $65 \%$ for FOSA (SI Tables S4-5). Seawater samples were extracted in duplicate and the variability of measured concentrations was found to be at most $23 \%$; the reported values for seawater were an average of the duplicate analysis. The limits of quantification (LOQs) were defined based on several criteria, including (i) the lowest concentration of standard on the calibration curve that could be accurately measured within $\pm 20 \%$ of its theoretical value; (ii) a signal-to-noise ratio equal to or greater than 10; (iii) concentration factor; and, (iv) sample volume. The LOQs of the present study were 5-10 pg/L for PFAAs and $20 \mathrm{pg} / \mathrm{L}$ for FOSA (SI Table S2b). The interlaboratory comparison between ALFONSE and MTM was limited to PFOA and PFOS, and their respective relative standard deviations for PFOA and PFOS were 27 and $15 \%$ at most (see SI for more details, including SI Table S6).

Modeled inputs of PFOS and PFOA to the Arctic Ocean. To help evaluate the contributions of atmospheric and oceanic inputs to observed PFOS and PFOA concentrations, we developed a three-compartment geochemical box model for the Arctic Ocean adapted from Soerensen et al. ${ }^{38}$ representing: (1) the polar mixed layer: PML, (2) the subsurface ocean (20-200 m depth including the halocline), and (3) the deep ocean (200 m - bottom). For 
PFOS, the model is forced by inputs from the Atlantic Ocean between 1958-2038 based on the 3-D ocean circulation model developed by Zhang et al. ${ }^{39}$ PFOS mass inflow is stratified by depth based on seawater inflow for the surface, subsurface and deep Arctic seawater. We do not include PFAS inputs from the Pacific Ocean since inflow of seawater is small relative to the Atlantic Ocean and no data are available on temporal changes in PFAS inputs for the Pacific. Atmospheric deposition is based on ice-core data from Young et al. ${ }^{16}$ We present model simulations forced by both the median (cumulatively: $2410 \mathrm{Mg}$ ) and low (842 Mg) emissions scenarios for continental PFOS discharges to the North Atlantic from North American and European wastewater and rivers reported by Zhang and co-workers ${ }^{39}$ between 1958 and 2038.

For PFOA, we do not have a comparable 3-D simulation to resolve oceanic inflow at the surface, subsurface and in deep waters. We therefore estimate only the contribution of atmospheric deposition to surface water (PML) concentrations based on deposition rates measured in the Devon Ice Cap from the Canadian High Arctic between 1993 and $2007 .{ }^{15}$ Deposition prior to 1993 was fixed at the lowest recorded value $\left(7 \mathrm{ng} / \mathrm{m}^{2} /\right.$ year). For recent years we assumed two scenarios representing deposition that continues from 2007 values and complete elimination. This allows us to estimate the relative contribution of atmospheric inputs compared to oceanic inflow.

\section{Results and Discussion}

PFAS concentrations and profiles. In total, 69 samples were analyzed for 39 PFASs in seawater, snow and melt pond water. Only thirteen PFASs (C6-C12 PFCAs; C6, 8, 10 PFSAs; MeFOSAA and EtFOSAA, and FOSA) showed detectable concentrations (individual compound range: $<5-343 \mathrm{pg} / \mathrm{L}$ ) (SI Table S7). Therefore, the following discussion will only focus on these thirteen PFASs. Figure 2 and SI Tables S7a-d show that the detection of 
PFASs in the four depth profiles was limited to the PML and halocline (150 m below the surface), except for the North Barents Sea (PS80/227) where PFOS was detected down to 250 $\mathrm{m}$ below surface. The detection frequency and range $(\%, \mathrm{pg} / \mathrm{L})$ of the 13 detectable PFASs are provided in SI Table S8.

PFASs in the Central Arctic Surface water. Surface water concentrations of total PFASs in the Central Arctic Ocean ranged from $11-174$ pg/L. Previous investigations reported total PFAS concentrations of $45-280 \mathrm{pg} / \mathrm{L}$ in surface water from the Greenland $\mathrm{Sea}^{21}$ and the average concentrations of PFOA and FOSA combined were $112 \mathrm{pg} / \mathrm{L}$ in the East Greenland Arctic Ocean. ${ }^{18}$ Average total PFAS concentrations were reported as $500 \pm 170 \mathrm{pg} / \mathrm{L}$ in surface water of the Arctic Ocean ${ }^{19}$ and $40-250$ pg/L in the Canadian Arctic. ${ }^{17}$ Results from this study (average total PFAS: 98 $\pm 73 \mathrm{pg} / \mathrm{L}$ ) were approximately 5-fold lower than previous measurements of PFAS concentrations in Arctic Ocean surface waters.

PFASs in the Arctic Ocean water column. In the four vertical water column profiles, the detection of PFAS was limited to the PML and halocline (150 m below the surface), except for the North Barents Sea (PS80/227) where PFOS was detected down to $250 \mathrm{~m}$ below surface. Among the four vertical profiles, maximum individual PFAS concentrations (pg/L) were as follows: 50 (PFOA), 47 (PFOS), 40 (PFBS), 39 (PFNA), 37 (PFHxA), 35 (PFHpA), 27 (PFDS), 22 (PFHxS), and 17 (PFUnDA). The composition of PFASs varied with location and depth, highlighting the combination of different sources (rivers, atmosphere, ocean currents) and circulation of the Arctic. Similar composition profiles were only observed in some layers of water columns (50 and 75 m below surface near the Pole - PS80/364 and 10 and $50 \mathrm{~m}$ below surface at the Amundsen basin - East of Gakkel Ridge - PS80/254). To better understand the interplay between PFASs sources and mixing in the Arctic Ocean, we need to take a closer look at water mass circulation. 
PFASs in Arctic Ocean water masses. The upper Arctic Ocean is strongly stratified and consists of different water masses distributed from the surface to the bottom, with different circulation patterns. ${ }^{40}$ In summer, with the sea ice melt and river run-off, the surface water of the Arctic forms the polar mixed layer (PML), which has a lower salinity compared to the deeper water layer. In the present study, the depth of the PML ranged from 10 to $30 \mathrm{~m}$ from surface, where we detected C6-C9 and C11 PFCAs, C4, C6, and C8 PFSAs (SI Table S7a). The PML is mixed by waves, ice rafting, and turbulence caused by the wind stress on the surface. Below the PML is the halocline, the layer above a deeper, warmer and saltier Atlantic Layer. ${ }^{40}$ In the current investigation, the depths of the halocline ranged from 75 to $150 \mathrm{~m}$ from surface, where we detected the same suite of PFASs as in the PML. Freezing seawater can change the salinity of seawater during brine formation, which might transport contaminants from the surface to the halocline layer. The different compositions of PFASs in seawater between the PML and the halocline layer (Figure 2) may be explained partly due to different mixing regimes and partly by atmospheric deposition or sea ice melt on a seasonal basis. The upward heat flux from the Atlantic layer warms the transition layer of halocline that prevents further sinking of the surface water, and thus reduces the vertical transport of contaminants to the deep and bottom water. ${ }^{40}$ However, transport (e.g., due to sinking) of contaminants bound to organic carbon or particles may also take place,,${ }^{41}$ as a recent study has shown accumulation of PCBs and PBDEs in deep-sea organisms. ${ }^{33}$

The ventilation age of the Atlantic layer water varies from 10 - 80 years, with the water masses closest to the cold halocline being youngest. ${ }^{42}$ The lifetime of tracers in the PML is typically $<1$ year, in the halocline $\sim 10$ years, in the Atlantic water $\sim 25$ years, and in Arctic Deep water $~ 75-300$ years. ${ }^{43,44}$ The depths of the Atlantic layer ranged from below the halocline to $1000 \mathrm{~m}$ depth, where PFNA and PFOS were detected in 150-250 m below surface the North Barents Sea (PS80/227) and PFBS was detected $150 \mathrm{~m}$ below surface in the 
Amundsen Basin - East Gakkel Ridge (PS80/275). The presence of PFASs in the Atlantic layer most likely reflects long-range oceanic transport, since pronounced vertical settling would result in penetration to greater depths, as was previously demonstrated for PCBs. ${ }^{29}$ Prior work shows particle settling in the North Atlantic is negligible as a transport pathway for PFASs compared to lateral ocean circulation..$^{32,39}$

Yamashita et al. reported surface water concentrations of 160-338 pg/L for PFOA, 15-36 $\mathrm{pg} / \mathrm{L}$ for PFNA, and 8.6-36 pg/L for PFOS in $2003 .{ }^{20}$ In the Labrador Sea and North Atlantic Ocean, they also detected PFOA at 50 and $20 \mathrm{pg} / \mathrm{L}$ down to $3000 \mathrm{~m}$. In the Atlantic layer in the Arctic Ocean sampled here, though, only PFOS (11- $37 \mathrm{pg} / \mathrm{L})$ and PFNA (13 pg/L) were detected in the North Barents Sea (PS80/227). Unexpectedly PFOA, typically a major PFASs, was not detected in this study above LOQ the $(5 \mathrm{pg} / \mathrm{L})$ in the waters deeper than $75 \mathrm{~m}$. At the locations further away from the Atlantic Ocean, such as Nansen Basin - West Gakkel Ridge (PS80/254), Amundsen Basin - East Gakkel Ridge (PS80/275), and near the Pole (PS80/364), no detectable PFASs were observed in the Atlantic layer. In summary, few PFASs were detected (at low concentrations, $<50 \mathrm{pg} / \mathrm{L}$, see Figure 2) in the Arctic Ocean water below the PML and halocline, implying a combination of dilution and delayed transport into the deeper Arctic water.

Concentrations of PFASs in the water column along the Arctic shelf. Concentrations of PFASs in water samples collected along the Chuckchi Sea shelf at different depths from nearshore to offshore are shown in Figure 3 and SI Tables 7e-k. PFOA was the dominant PFAS in almost all samples (detection frequency: 100\%; mean $44 \mathrm{ng} / \mathrm{L}$, median $42 \mathrm{ng} / \mathrm{L}$ ), followed by PFOS (91\%; mean $14 \mathrm{ng} / \mathrm{L}$, median $10 \mathrm{ng} / \mathrm{L})$ and PFNA (88\%; mean and median of $14 \mathrm{ng} / \mathrm{L})$. Concentrations were in general comparable to those measured in the Central Arctic Ocean. Different PFAS composition profiles were observed between the samples collected along the Arctic shelf and the Arctic Ocean. One of the reasons might be the 
complexity in water sources. The water sources of the Arctic Ocean are mainly Atlantic water and sea ice melt, whereas the Arctic shelf represents a combination of Atlantic water, Pacific water, sea ice melt and river run-off. ${ }^{28}$ Several observations stand out: First, the ratios of PFOA/PFNA in two different sampling routes from nearshore to offshore increased (Stations HLY1203/70 and 71: 1.6, Station HLY1203/66: 4.9, Station HLY1203/62: 7.9; and Station HLY1203/72: 1.9, Station HLY1203/76: 3.6, Station HLY1203/78: 5.3). Second, PFDA was only detected in samples collected from nearshore stations (HLY1203/70 and 71). The decreasing contribution of PFNA to PFOA from nearshore to offshore areas and detection of PFDA limited to nearshore area suggested these sources might come from river run-off to the nearshore area, and then diluted when getting into offshore area. Seasonally varying fresh water inputs are thought to be important sources of other contaminants to the Arctic surface waters. ${ }^{24-26}$ Third, MeFOSAA was detected in water sample from the Arctic shelf. MeFOSAA is an oxidation product of MeFOSE, which was primarily incorporated into polymeric materials as a surface treatment for products like carpets and textiles. ${ }^{45,46}$ It is also believed to be a PFOS precursor. In contrast to the anionic nature and persistence of PFCAs and PFSAs, MeFOSE is a neutral and volatile compound; it is expected to present in the atmosphere and will ultimately degrade to PFOS under environmental or biological condition. ${ }^{45}$ An earlier study also showed the detection of MeFOSE in the Arctic atmosphere.${ }^{47}$ Fourth, the PFAS composition profiles were quite different at the water layers between 50 m (PFOA: 69\%, PFBS: 10\%, PFHxS: 10\%; PFOS: 12\%) and 76 m (PFOA: 78\%; PFNA: 22\%) depth at Station HLY1203/62. Different composition profiles of PFAS between the nearshore and offshore samples may be explained by different sources (river run-off at the near shore) and the dilution effect by ocean water. The different PFAS compositions between the surface and bottom waters may be explained partly by the contribution of ice melt in the surface (changes in salinity from the surface to the bottom). 

mostly first year ice, integrating PFAS deposition from up to one year. ${ }^{48}$ More PFASs (PFUnDA, FOSA, and EtFOSAA) were detected in melt pond water and snow samples compared to seawater from the Arctic shelf and central basin (SI Table S7l). Snow samples showed detectable concentrations of PFCAs (C6-C12), PFSAs (C8 and C10), MeFOSAA, EtFOSAA and FOSA (Figure 4). Various PFCAs were detected at concentrations greater than 100 pg/L, including PFHxA, PFOA, PFNA, PFDA, PFOS and FOSA. Total PFAS concentrations $(403 \pm 405 \mathrm{pg} / \mathrm{L})$ in the present investigation were much lower than the snow samples collected from Japan and the U.S. (concentrations in the ng/L range) ${ }^{49}$ and similar or greater to previously reported for the Devon ice cap ${ }^{15,16}$ and surface snow from glacier in Svalbard, Norway. ${ }^{50}$ Relatively high total PFASs were observed at Station 5 - PS80/323 (1600 pg/L; Station 1: $298 \mathrm{pg} / \mathrm{L}$ and Station 8: $368 \mathrm{pg} / \mathrm{L}$ ), which was at similar to concentrations in snow samples collected downstream of Svalbard, Norway (1470 pg/L). ${ }^{50}$ Spatial trends might imply that proximity to Eurasian continental atmospheric emissions were a main source of elevated PFASs in snow (see SI Table S9).

Snow has been suggested to be an effective scavenger of PFAS in the atmosphere; enhanced PFAS concentrations in snow are interpreted as evidence for a primary source of PFAA to the Arctic via atmospheric oxidation of volatile precursors. ${ }^{16}$ Atmospheric oxidation of volatile FTOHs under low NOx conditions may form PFCAs of different chain lengths, ${ }^{13,51}$ whereas atmospheric oxidation of volatile perfluorooctane sulfonamidoethanols (e.g., FOSE) may result in different perfluorooctane sulfonamido derivatives as well as PFOS. ${ }^{52,53}$ Intermediate compounds such as saturated and unsaturated fluorotelomer acids (FTCAA/FTUCAs: 6:2, 8:2, and 10:2) were suggested to be the connection between the volatile fluorotelomer precursors and PFCAs; they were below their respective detection limits in this study (FTCAs: 1000 pg/L; FTUCA: 10 pg/L). In a smog chamber study, Ellis et 
al. ${ }^{13}$ observed a production of approximately 1:1 ratio of C8 and C9 PFCAs after oxidation of 8:2 FTOH using the $\mathrm{Cl}$ atom as surrogates to $\mathrm{OH}$ radicals. A recent investigation showed that heterogeneous photooxidation of 6:2 FTOH yielded C6 and C5 PFCAs in a ratio ranging from 1:1 to $6: 1$, depending on the surface of the substrates and the length of illuminated period. ${ }^{54}$ Results from these studies imply that observed ratios ranging from 1:1 to 6:1 between different pairs of PFCAs imply the occurrence of oxidation of fluorotelomer-based precursors (e.g., FTOH). On the other hand, the ratio between C8 and C9 PFCAs due to direct global emission was reported to be approximately $8: 1 ;^{12}$ and the biotransformation of $8: 2 \mathrm{FTOH}$ through beta oxidation preferentially yielded PFOA. ${ }^{55}$ Based on these two results, a recent study suggested that the ratio between $\mathrm{C} 8$ and C9 PFCAs due to direct source and biotransformation might be greater than 8:1. ${ }^{56}$ Although we did not detect intermediates in snow samples, the ratios between different pairs of PFCAs may be an indicator of atmospheric oxidation of volatile fluorotelomer precursors (see SI Table S10). The ratios of

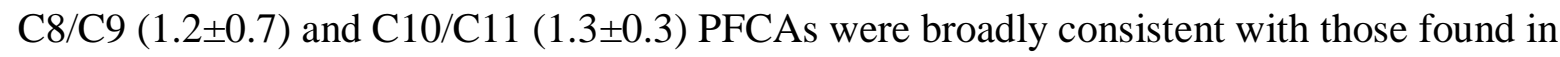
high Arctic ice caps (C8/C9: $1.5 \pm 0.8$ and C10/C11: 0.9 \pm 0.8$)$. Although variable ratios of C6/C7 PFCAs $(2.4 \pm 1.8)$ were observed, our results were within the ratio obtained by heterogeneous photooxidation of 6:2 FTOH.

Modeled PFAS fluxes into the Arctic Ocean. Figure 5 shows the results of geochemical box model simulations for PFOS and PFOA in the Arctic Ocean. For PFOS, modeled concentrations are highest in the PML and halocline, consistent with the observations reported in Figures 2 and 3. For 2012, the modeled PFOS concentration in the PML and subsurface waters were between 11-36 pg/L (low and median scenarios) and agreed well with the mean measured value of $17 \mathrm{pg} / \mathrm{L}$ in the PML (range: <5-41). For PFOS, the modeled contribution of atmospheric deposition to surface water concentrations was minor at $<3 \mathrm{pg} / \mathrm{L}$ (or up to $30 \%$ of observed concentrations; SI Figure S3). In deeper waters, the 
modeled value (range: $5-15 \mathrm{pg} / \mathrm{L})$ is slightly higher than observations $(<5 \mathrm{pg} / \mathrm{L})$, suggesting the lower emissions scenario is more consistent with observed concentrations. Despite relatively low concentrations in deep Arctic waters due to dilution and mixing, the majority of the PFOS mass (74\%, Figure 5 top panel) is still expected in this region of water column. Only $4 \%$ of the modeled PFOS mass is found in the PML and $22 \%$ in the mid-depth/halocline waters according to this model calculation. Although PFOS concentrations in surface and mid-depth waters peaked in the early 2000s, concentrations in deeper waters are still increasing based on model simulations and thus may be detectable in future ocean campaigns. For PFOA, modeled mean concentrations in the PML from atmospheric deposition are estimated to be between 11 and $19 \mathrm{pg} / \mathrm{L}$, depending on assumptions related to recent PFOA inputs (Figure 5 bottom panel), compared to the mean observed concentration in surface waters of $32 \pm 15 \mathrm{pg} / \mathrm{L}$. While the PFOS burden in Arctic seawater is accounted for mainly by North Atlantic inputs, modeling results for PFOA suggest approximately 34-59\% of surface water concentrations are from atmospheric inputs. These results are consistent with a variety of studies that show atmospheric transport and degradation of PFOA precursors is a more important source to the global ocean than for PFOS where direct discharges are estimated to comprise more than $95 \%$ of total inputs. ${ }^{57-59}$

Mass budget of PFASs in the Arctic Ocean. We derived mass budgets for PFASs in sampling regions of the Arctic basin, including the central Arctic Ocean, the Beaufort/Chuckhi Sea and the ice layer (Table 1). Combining volumes and measured PFAS concentrations resulted in the following PFAS budgets (in Mg) for the surface Central Arctic Ocean: PFOA $8.6 \pm 6.8 ;$ PFOS $4.8 \pm 4.4 ;$ PFNA $4.2 \pm 3.4$; PFHpA $3.9 \pm 3.8$; PFHxA $3.6 \pm$ 3.8; PFBS 3.6 \pm 2.4 , and PFHxS $2.3 \pm 2.1 \mathrm{Mg}$. In total, there are $31 \pm 26 \mathrm{Mg}$ of PFASs present in the upper Arctic Ocean water (Table 1). We note that the amount of PFOA and PFOS at $1 / 2$ LOQ $(2.5 \mathrm{pg} / \mathrm{L})$ in the Atlantic water layer down to $1000 \mathrm{~m}$ would add $10 \mathrm{Mg}$ per congener. 

dominated by PFOA (almost $3 \mathrm{Mg}$ ), with $900 \mathrm{~kg}$ from PFNA and almost $1 \mathrm{Mg}$ from PFOS (Table 1). In August 2012, a total of $4.1 \times 10^{6} \mathrm{~km}^{2}$ were covered by ice, most of which was thin first year ice. ${ }^{60}$ Assuming a $1 \mathrm{~m}$ thickness (a rough estimation) across the Arctic, and average PFAS concentrations derived from snow and meltwater resulted in a stock of around $1.8 \mathrm{Mg}$ of total PFASs in ice, dominated by $>400 \mathrm{~kg}$ each from PFNA, PFOA and PFOS. Overall, the PFAS budgets in the Arctic Ocean derived here are lower than modeled masses for PFOS shown in Figure 5 due to different regions of the Arctic considered, and in comparison to mass budgets present in the North Atlantic (200 Mg in surface layer). ${ }^{61}$

Overall, we find the PML and halocline in the Arctic Ocean already contain more PFASs than PCBs (2 Mg), due to the much greater dissolved PFAS concentrations. Comparably greater proportions of PCB inputs have reached the deeper water masses, where an estimated $35 \mathrm{Mg}$ are contained. ${ }^{29}$

Environmental Implications. Both atmospheric and oceanic transport of PFASs have been proposed as important long-range transport mechanisms. ${ }^{12,14}$ Detection of PFAS in snow samples in this study suggests the ongoing importance of atmospheric deposition for some PFCAs, which may come from atmospheric oxidation of volatile precursor compounds or particles. We report low concentrations of PFASs in the Atlantic water layer of the Arctic Ocean, which is consistent with mixing and dilution of inputs from the Atlantic Ocean. Yet PFAS concentrations in deeper water masses are predicted to increase over time (Figure 5). A recent investigation calculated vertical transport of PFASs based on an estimate of the settling of organic matter and measured concentrations of PFASs bound to particles. The authors suggesting the biological pump a sink of some PFASs. ${ }^{62}$ Our observations of limited penetration of PFASs at depth suggests this flux must be minimal for most areas of the Arctic. Results for PFASs contrast vertical profiles of PCBs and PBDEs in the Arctic ${ }^{29,30}$ indicating 
vertical transport processes are weaker and potentially irrelevant for PFASs, as suggested by some modeling work. ${ }^{39}$

With the implementation of Stockholm Convention and PFOA Stewardship program, the emission of PFOS-based and PFOA and higher-chain length PFCAs should be greatly reduced and the inputs of these PFASs are expected to decrease. By contrast, short-chain PFASs have been introduced into market as replacement and their environmental levels are expected to increase. A recent study showed increased contribution of PFBS to PFOS in marine mammals during the period 2002 to 2012 in South China. ${ }^{63}$ Although analytical methods are available for measuring some short-chain PFASs (C4-C7 PFAAs), more sensitive chromatographic techniques should be developed to measure low levels in the samples for some 'ultra-short'-chain PFAAs (e.g., C2 and C3). Long term PFAS monitoring in snow samples from different ice stations may be useful to determine the input of PFAS via atmospheric deposition to the Arctic.

Supporting Information. Details on the sampling, locations and auxiliary measurements, PFASs' chemical analysis, concentrations and QA/QC measures. This material is available free of charge via the Internet at http://pubs.acs.org.

\section{Acknowledgements}

We greatly acknowledge the officers and crews for assistance during sampling; Polarstern:

Drs. Catherine Lalande and Antje Boetius (Alfred Wegener Institute Bremerhaven Germany); Healy: Dr. Jeremy T. Mathis and Natalie M Monacci (University of Alaska Fairbanks). R.L. and E.M.S. acknowledge support from NSF's Office of Polar Programs (ARC 1203486, 1203496) to study the transport pathways of organic pollutants into the Arctic Ocean. S.A.M. 
436 acknowledges the fund from Canada Foundation for Innovation: Advanced Laboratory for

437 Fluorinated and Other New Substances in the Environment (ALFONSE).

438

439

440

441

442

443

444

445

446

447

448

449 
(1) Buck, R. C.; Franklin, J.; Berger, U.; Conder, J. M.; Cousins, I. T.; de Voogt, P.; Jensen, A. A.; Kannan, K.; Mabury, S. A.; van Leeuwen, S. P. J. Perfluoroalkyl and polyfluoroalkyl substances in the environment: Terminology, classification, and origins. Integr. Environ. Assess. Manag. 2011, 7 (4), 513-541.

(2) Ahrens, L.; Xie, Z.; Ebinghaus, R. Distribution of perfluoroalkyl compounds in seawater from Northern Europe, Atlantic Ocean, and Southern Ocean. Chemosphere 2010, 78 (8), 1011-1016.

(3) Ahrens, L.; Barber, J. L.; Xie, Z.; Ebinghaus, R. Longitudinal and latitudinal distribution of perfluoroalkyl compounds in the surface water of the Atlantic Ocean. Environ. Sci. Technol. 2009, 43 (9), 3122-3127.

(4) Butt, C. M.; Berger, U.; Bossi, R.; Tomy, G. T. Levels and trends of poly- and perfluorinated compounds in the arctic environment. Sci. Total Environ. 2010, 408 (15), 2936-2965.

(5) Giesy, J. P.; Kannan, K. Global distribution of perfluorooctane sulfonate in wildlife. Environ. Sci. Technol. 2001, 35 (7), 1339-1342.

(6) González-Gaya, B.; Dachs, J.; Roscales, J. L.; Caballero, G.; Jiménez, B. Perfluoroalkylated Substances in the Global Tropical and Subtropical Surface Oceans. Environ. Sci. Technol. 2014, 48 (22), 13076-13084.

(7) Houde, M.; Martin, J. W.; Letcher, R. J.; Solomon, K. R.; Muir, D. C. G. Biological monitoring of polyfluoroalkyl substances: A review. Environ. Sci. Technol. 2006, 40 (11), 3463-3473.

(8) Martin, J. W.; Mabury, S. A.; Solomon, K. R.; Muir, D. C. G. Bioconcentration and tissue distribution of perfluorinated acids in rainbow trout (Oncorhynchus mykiss). Environ. Toxicol. Chem. SETAC 2003, 22 (1), 196-204.

(9) Martin, J. W.; Mabury, S. A.; Solomon, K. R.; Muir, D. C. G. Dietary accumulation of perfluorinated acids in juvenile rainbow trout (Oncorhynchus mykiss). Environ. Toxicol. Chem. SETAC 2003, 22 (1), 189-195.

(10) Yamashita, N.; Kannan, K.; Taniyasu, S.; Horii, Y.; Petrick, G.; Gamo, T. A global survey of perfluorinated acids in oceans. Mar. Pollut. Bull. 2005, 51 (8-12), 658-668.

(11) Stockholm Convention. (POPs PFOS, its salts and PFOSF were listed in Annex B in the Conference of the Parties 4 of the Stockholm Convention (COP-4) (http://chm.pops.int/Convention/Pressrelease/COP4Geneva9May2009/tabid/542/langu ages/en-US/Default.aspx); 2009.

(12) Prevedouros, K.; Cousins, I. T.; Buck, R. C.; Korzeniowski, S. H. Sources, fate and transport of perfluorocarboxylates. Environ. Sci. Technol. 2006, 40 (1), 32-44.

(13) Ellis, D. A.; Martin, J. W.; De Silva, A. O.; Mabury, S. A.; Hurley, M. D.; Sulbaek Andersen, M. P.; Wallington, T. J. Degradation of fluorotelomer alcohols: a likely atmospheric source of perfluorinated carboxylic acids. Environ. Sci. Technol. 2004, 38 (12), 3316-3321.

(14) Ellis, D. A.; Martin, J. W.; Mabury, S. A.; Hurley, M. D.; Andersen, M. P. S.; Wallington, T. J. Atmospheric lifetime of fluorotelomer alcohols. Environ. Sci. Technol. 2003, 37 (17), 3816-3820.

(15) MacInnis, J. J.; French, K.; Muir, D. C. G.; Spencer, C.; Criscitiello, A.; De Silva, A. O.; Young, C. J. Emerging investigator series: a 14-year depositional ice record of perfluoroalkyl substances in the High Arctic. Env. Sci Process. Impacts 2017, 19 (1), 22-30. 
(16) Young, C. J.; Furdui, V. I.; Franklin, J.; Koerner, R. M.; Muir, D. C. G.; Mabury, S. A. Perfluorinated acids in Arctic snow: new evidence for atmospheric formation. Environ. Sci. Technol. 2007, 41 (10), 3455-3461.

(17) Benskin, J. P.; Muir, D. C. G.; Scott, B. F.; Spencer, C.; De Silva, A. O.; Kylin, H.; Martin, J. W.; Morris, A.; Lohmann, R.; Tomy, G.; et al. Perfluoroalkyl acids in the atlantic and Canadian arctic oceans. Environ. Sci. Technol. 2012, 46, 5815-5823.

(18) Busch, J.; Ahrens, L.; Xie, Z.; Sturm, R.; Ebinghaus, R. Polyfluoroalkyl compounds in the East Greenland Arctic Ocean. J. Environ. Monit. JEM 2010, 12 (6), 1242-1246.

(19) Cai, M.; Zhao, Z.; Yin, Z.; Ahrens, L.; Huang, P.; Cai, M.; Yang, H.; He, J.; Sturm, R.; Ebinghaus, R.; et al. Occurrence of perfluoroalkyl compounds in surface waters from the North Pacific to the Arctic Ocean. Environ. Sci. Technol. 2012, 46 (2), 661-668.

(20) Yamashita, N.; Kannan, K.; Taniyasu, S.; Horii, Y.; Petrick, G.; Gamo, T. A global survey of perfluorinated acids in oceans. Mar. Pollut. Bull. 2005, 51 (8-12), 658-668.

(21) Zhao, Z.; Xie, Z.; Möller, A.; Sturm, R.; Tang, J.; Zhang, G.; Ebinghaus, R. Distribution and long-range transport of polyfluoroalkyl substances in the Arctic, Atlantic Ocean and Antarctic coast. Environ. Pollut. 2012, 170, 71-77.

(22) Yamashita, N.; Taniyasu, S.; Petrick, G.; Wei, S.; Gamo, T.; Lam, P. K. S.; Kannan, K. Perfluorinated acids as novel chemical tracers of global circulation of ocean waters. Chemosphere 2008, 70 (7), 1247-1255.

(23) The freshwater budget of the Arctic Ocean: [proceedings of the NATO Advanced Research Workshop on the Freshwater Budget of the Arctic Ocean, Tallinn, Estonia, 27 April - 1 May 1998]; Lewis, E. L., Ed.; NATO science series Series 2, Environmental security; Kluwer Acad. Publ: Dordrecht, 2000.

(24) Fahrbach, E.; Meincke, J.; Østerhus, S.; Rohardt, G.; Schauer, U.; Tverberg, V.; Verduin, J. Direct measurements of volume transports through Fram Strait. Polar Res. 2001, 20 (2), 217-224.

(25) Schauer, U.; Loeng, H.; Rudels, B.; Ozhigin, V. K.; Dieck, W. Atlantic Water flow through the Barents and Kara Seas. Deep Sea Res. Part Oceanogr. Res. Pap. 2002, 49 (12), 2281-2298.

(26) Woodgate, R. A.; Aagaard, K.; Weingartner, T. J. Monthly temperature, salinity, and transport variability of the Bering Strait through flow: BERING STRAIT THROUGH FLOW. Geophys. Res. Lett. 2005, 32 (4), 1-4.

(27) Melling, H.; Agnew, T. A.; Falkner, K. K.; Greenberg, D. A.; Lee, C. M.; Münchow, A.; Petrie, B.; Prinsenberg, S. J.; Samelson, R. M.; Woodgate, R. A. Fresh-Water Fluxes via Pacific and Arctic Outflows Across the Canadian Polar Shelf. In ArcticSubarctic Ocean Fluxes; Dickson, R. R., Meincke, J., Rhines, P., Eds.; Springer Netherlands: Dordrecht, 2008; pp 193-247.

(28) Woodgate, R. Arctic Ocean Circulation: Going around at the top of the world. Nat. Educ. Knowl. 2013, 4, p8. https://www.nature.com/scitable/knowledge/library/arctic-ocean-circulation-goingaround-at-the-102811553

(29) Sobek, A.; Gustafsson, Ö. Deep water masses and sediments are main compartments for polychlorinated biphenyls in the Arctic Ocean. Environ. Sci. Technol. 2014, 48 (12), 6719-6725.

(30) Salvadó, J. A.; Sobek, A.; Carrizo, D.; Gustafsson, Ö. Observation-Based Assessment of PBDE Loads in Arctic Ocean Waters. Environ. Sci. Technol. 2016, 50 (5), 22362245.

(31) Harner, T.; Kylin, H.; Bidleman, T. F.; Strachan, W. M. J. Removal of $\alpha$ - and $\gamma$ Hexachlorocyclohexane and Enantiomers of $\alpha$-Hexachlorocyclohexane in the Eastern Arctic Ocean. Environ. Sci. Technol. 1999, 33 (8), 1157-1164. 
(32) Sun, C.; Soltwedel, T.; Bauerfeind, E.; Adelman, D. A.; Lohmann, R. Depth Profiles of Persistent Organic Pollutants in the North and Tropical Atlantic Ocean. Environ. Sci. Technol. 2016, 50 (12), 6172-6179.

(33) Jamieson, A. J.; Malkocs, T.; Piertney, S. B.; Fujii, T.; Zhang, Z. Bioaccumulation of persistent organic pollutants in the deepest ocean fauna. Nat. Ecol. Evol. 2017, 1 (3), 0051. doi:10.1038/s41559-016-0051

(34) Healy 1203; http://icefloe.net/2012_hly1203.

(35) Die Expedition ARK-XXVII/3. Alfred-Wegener-Institut, Helmholtz-Zentrum Fur Polar und Meeresforschung. https://epic.awi.de/36855/1/ARK-XXVII_3_weekly_reports.pdf

(36) ISO. ISO25101. Water quality - Determination of perfluorooctanesulfonate (PFOS) and perfluorooctanoate (PFOA) - Method for unfiltered samples using solid phase extraction and liquid chromatography/mass spectrometry; 2009.

(37) Yeung, L. W. Y.; Robinson, S. J.; Koschorreck, J.; Mabury, S. A. Part I. A temporal study of PFCAs and their precursors in human plasma from two German cities 19822009. Environ. Sci. Technol. 2013, 47 (8), 3865-3874.

(38) Soerensen, A. L.; Jacob, D. J.; Schartup, A. T.; Fisher, J. A.; Lehnherr, I.; St. Louis, V. L.; Heimbürger, L.-E.; Sonke, J. E.; Krabbenhoft, D. P.; Sunderland, E. M. A mass budget for mercury and methylmercury in the Arctic Ocean: ARCTIC OCEAN HG AND MEHG MASS BUDGET. Glob. Biogeochem. Cycles 2016, 30 (4), 560-575.

(39) Zhang, X.; Zhang, Y.; Sunderland, E. M. Assessment of the fate and transport of perfluoroalkyl acids in the ocean using a high-resolution global oceanic circulation model; Society of Environmental Toxicology and Chemistry 35th Annual Meeting, Vancouver, BC, Canada., 2014.

(40) Rudels, B.; Jones, E. P.; Anderson, L. G.; Kattner, G. On the intermediate depth waters of the Arctic Ocean. In Geophysical Monograph Series; Johannessen, O. M., Muench, R. D., Overland, J. E., Eds.; American Geophysical Union: Washington, D. C., 1994; Vol. 85, pp 33-46.

(41) Waples, J. T.; Klump, J. V. Vertical and horizontal particle transport in the coastal waters of a large lake: An assessment by sediment trap and thorium-234 measurements: Particle Transport in Coastal Waters. J. Geophys. Res. Oceans 2013, 118 (10), 53765397.

(42) Tanhua, T.; Jones, E. P.; Jeansson, E.; Jutterström, S.; Smethie, W. M.; Wallace, D. W. R.; Anderson, L. G. Ventilation of the Arctic Ocean: Mean ages and inventories of anthropogenic $\mathrm{CO}_{2}$ and CFC-11. J. Geophys. Res. 2009, 114, 1-11.

(43) Bönisch, G.; Schlosser, P. Deep water formation and exchange rates in the Greenland/Norwegian Seas and the Eurasian Basin of the Arctic Ocean derived from tracer balances. Prog. Oceanogr. 1995, 35 (1), 29-52.

(44) Schlosser, P.; Bayer, R.; Bönisch, G.; Cooper, L. W.; Ekwurzel, B.; Jenkins, W. J.; Khatiwala, S.; Pfirman, S.; Smethie, W. M. Pathways and mean residence times of dissolved pollutants in the ocean derived from transient tracers and stable isotopes. Sci. Total Environ. 1999, 237-238, 15-30.

(45) 3M. 1999. Fluorochemical Use, Distribution and Release Overview, U.S. EPA Public Docket AR226-0550; U.S. Environmental Protection Agency: Washington, DC,.

(46) Olsen, G. W.; Church, T. R.; Larson, E. B.; van Belle, G.; Lundberg, J. K.; Hansen, K. J.; Burris, J. M.; Mandel, J. H.; Zobel, L. R. Serum concentrations of perfluorooctanesulfonate and other fluorochemicals in an elderly population from Seattle, Washington. Chemosphere 2004, 54 (11), 1599-1611. 
(47) Shoeib, M.; Harner, T.; Vlahos, P. Perfluorinated chemicals in the arctic atmosphere. Environ. Sci. Technol. 2006, 40 (24), 7577-7583.

(48) Boetius, A.; Albrecht, S.; Bakker, K.; Bienhold, C.; Felden, J.; Fernandez-Mendez, M.; Hendricks, S.; Katlein, C.; Lalande, C.; Krumpen, T.; et al. Export of Algal Biomass from the Melting Arctic Sea Ice. Science 2013, 339 (6126), 1430-1432.

(49) Kwok, K. Y.; Taniyasu, S.; Yeung, L. W. Y.; Murphy, M. B.; Lam, P. K. S.; Horii, Y.; Kannan, K.; Petrick, G.; Sinha, R. K.; Yamashita, N. Flux of perfluorinated chemicals through wet deposition in Japan, the United States, and several other countries. Environ. Sci. Technol. 2010, 44 (18), 7043-7049.

(50) Kwok, K. Y.; Yamazaki, E.; Yamashita, N.; Taniyasu, S.; Murphy, M. B.; Horii, Y.; Petrick, G.; Kallerborn, R.; Kannan, K.; Murano, K.; et al. Transport of perfluoroalkyl substances (PFAS) from an arctic glacier to downstream locations: implications for sources. Sci. Total Environ. 2013, 447, 46-55.

(51) Hurley, M. D.; Misner, J. A.; Ball, J. C.; Wallington, T. J.; Ellis, D. A.; Martin, J. W.; Mabury, S. A.; Sulbaek Andersen, M. P. Atmospheric chemistry of $\mathrm{CF} 3 \mathrm{CH} 2 \mathrm{CH} 2 \mathrm{OH}$ : kinetics, mechanisms and products of $\mathrm{Cl}$ atom and $\mathrm{OH}$ radical initiated oxidation in the presence and absence of NOX. J. Phys. Chem. A 2005, 109 (43), 9816-9826.

(52) D'eon, J. C.; Hurley, M. D.; Wallington, T. J.; Mabury, S. A. Atmospheric chemistry of $\mathrm{N}$-methyl perfluorobutane sulfonamidoethanol, C4F9SO2N(CH3) $\mathrm{CH} 2 \mathrm{CH} 2 \mathrm{OH}$ : kinetics and mechanism of reaction with $\mathrm{OH}$. Environ. Sci. Technol. 2006, 40 (6), 1862-1868.

(53) Martin, J. W.; Ellis, D. A.; Mabury, S. A.; Hurley, M. D.; Wallington, T. J. Atmospheric chemistry of perfluoroalkanesulfonamides: kinetic and product studies of the $\mathrm{OH}$ radical and $\mathrm{Cl}$ atom initiated oxidation of $\mathrm{N}$-ethyl perfluorobutanesulfonamide. Environ. Sci. Technol. 2006, 40 (3), 864-872.

(54) Styler, S. A.; Myers, A. L.; Donaldson, D. J. Heterogeneous photooxidation of fluorotelomer alcohols: a new source of aerosol-phase perfluorinated carboxylic acids. Environ. Sci. Technol. 2013, 47 (12), 6358-6367.

(55) Wang, N.; Szostek, B.; Buck, R. C.; Folsom, P. W.; Sulecki, L. M.; Gannon, J. T. 8-2 Fluorotelomer alcohol aerobic soil biodegradation: Pathways, metabolites, and metabolite yields. Chemosphere 2009, 75 (8), 1089-1096.

(56) Rankin, K.; Mabury, S. A.; Jenkins, T. M.; Washington, J. W. A North American and global survey of perfluoroalkyl substances in surface soils: Distribution patterns and mode of occurrence. Chemosphere 2016, 161, 333-341.

(57) Armitage, J. M.; Schenker, U.; Scheringer, M.; Martin, J. W.; MacLeod, M.; Cousins, I. T. Modeling the Global Fate and Transport of Perfluorooctane Sulfonate (PFOS) and Precursor Compounds in Relation to Temporal Trends in Wildlife Exposure. Environ. Sci. Technol. 2009, 43 (24), 9274-9280.

(58) Armitage, J. M.; MacLeod, M.; Cousins, I. T. Modeling the Global Fate and Transport of Perfluorooctanoic Acid (PFOA) and Perfluorooctanoate (PFO) Emitted from Direct Sources Using a Multispecies Mass Balance Model. Environ. Sci. Technol. 2009, 43 (4), 1134-1140.

(59) Wania, F. A Global Mass Balance Analysis of the Source of Perfluorocarboxylic Acids in the Arctic Ocean. Environ. Sci. Technol. 2007, 41 (13), 4529-4535.

(60) National Snow \& Ice Data Center; Arctic Sea Ice News \& Analysis. Arctic sea ice extent settles at record seasonal minimum. September 19, 2012. http://nsidc.org/arcticseaicenews/2012/09/arctic-sea-ice-extent-settles-at-recordseasonal-minimum/ 
(61) Lohmann, R.; Jurado, E.; Dijkstra, H. A.; Dachs, J. Vertical eddy diffusion as a key mechanism for removing perfluorooctanoic acid (PFOA) from the global surface oceans. Environ. Pollut. 2013, 179, 88-94.

(62) Casal, P.; González-Gaya, B.; Zhang, Y.; Reardon, A. J. F.; Martin, J. W.; Jiménez, B.; Dachs, J. Accumulation of Perfluoroalkylated Substances in Oceanic Plankton. Environ. Sci. Technol. 2017, 51 (5), 2766-2775.

(63) Lam, J. C. W.; Lyu, J.; Kwok, K. Y.; Lam, P. K. S. Perfluoroalkyl Substances (PFASs) in Marine Mammals from the South China Sea and Their Temporal Changes 20022014: Concern for Alternatives of PFOS? Environ. Sci. Technol. 2016, 50 (13), 67286736. 
Table 1: Average concentrations ( $\mathrm{pg} / \mathrm{L})$, volumes $\left(\mathrm{km}^{3}\right)$ for the surface water of the Central Arctic and Beaufort/Chuckchi Seas and corresponding mass budgets (kg) for PFASs

\begin{tabular}{|c|c|c|c|c|c|c|c|c|c|}
\hline \multicolumn{2}{|l|}{ Central Arctic } & \multirow{2}{*}{$\begin{array}{c}\text { PFHxA } \\
11\end{array}$} & \multirow{2}{*}{$\begin{array}{c}\text { PFHpA } \\
12\end{array}$} & \multirow{2}{*}{$\begin{array}{c}\text { PFOA } \\
25\end{array}$} & \multirow{2}{*}{$\begin{array}{c}\text { PFNA } \\
13\end{array}$} & \multirow{2}{*}{$\begin{array}{c}\text { PFBS } \\
11\end{array}$} & \multirow{2}{*}{$\begin{array}{c}\text { PFHxS } \\
7\end{array}$} & \multirow{2}{*}{$\begin{array}{c}\text { PFOS } \\
14\end{array}$} & \multirow[t]{2}{*}{$\begin{array}{c}\text { sum } \\
\text { PFASs }\end{array}$} \\
\hline $\begin{array}{l}\text { Volume of surface } \\
\text { ocean }\left(\mathrm{km}^{3}\right)\end{array}$ & Average conc $c^{a}$ & & & & & & & & \\
\hline \multirow[t]{3}{*}{337000} & S.D. & 11 & 11 & 20 & 10 & 7 & 6 & 13 & \\
\hline & $\operatorname{mass}(\mathbf{k g})$ & 3590 & 3940 & 8550 & 4230 & 3590 & 2330 & 4850 & 31100 \\
\hline & S.D. & 3790 & 3760 & 6810 & 3380 & 2430 & 2190 & 4470 & 26800 \\
\hline Beaufort/ Chukchi & Average conc ${ }^{b}$ & & & 42 & 13 & & & 14 & 79 \\
\hline Volume $\left(\mathrm{km}^{3}\right)$ & S.D. & & & 19 & 7 & & & 9 & 32 \\
\hline \multirow[t]{2}{*}{71700} & $\operatorname{mass}(\mathbf{k g})$ & & & 3030 & 899 & & & 982 & 4910 \\
\hline & S.D. & & & 1329 & 476 & & & 671 & 2480 \\
\hline $\begin{array}{l}\text { Snow/meltpond } \\
\text { water }\end{array}$ & Average conc & 69 & 31 & 115 & 107 & & 6 & 99 & \\
\hline Volume $\left(\mathrm{km}^{3}\right)$ & S.D. & 58 & 13 & 101 & 86 & & 7 & 136 & \\
\hline 4100 & $\operatorname{mass}(\mathbf{k g})$ & 283 & 127 & 472 & 439 & & 25 & 406 & 1750 \\
\hline & S.D. & 238 & 53 & 414 & 353 & & 29 & 558 & 1640 \\
\hline
\end{tabular}

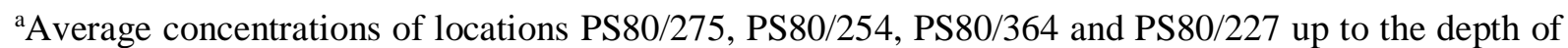
$75 \mathrm{~m}$ from surface; ${ }^{\mathrm{b}}$ Average concentrations of locations HL1203/72, HL1203/76, HL1203/78, HL1203/70, HL1203/71, HL1203/66, and HL1203/62 up to the depth of 75m from surface; Half LOQ was used for calculating the average value when the sample was below LOQ; S.D. denotes standard deviation of the average values. 
Figure 1. Map of stations occupied for this study. Sea-ice and melt-ponds were sampled at stations denoted '*'. Vertical profiles to a depth of $>2000 \mathrm{~m}$ were obtained at Stations 227 , 364, 254, and 275 collected in October 2012 on the research icebreaker Polarstern. Profiles on the shelf were $<400 \mathrm{~m}$ (Stations 62-78) collected in August/September 2012 the United States Coast Guard icebreaker Healy. (Red and black lines indicate circulation of respective intermediate and deep waters of Atlantic origin; green lines indicate major freshwater input by rives; yellow lines indicate the Pacific water flux through Bering Strait. The map was obtained from Ocean Data View)

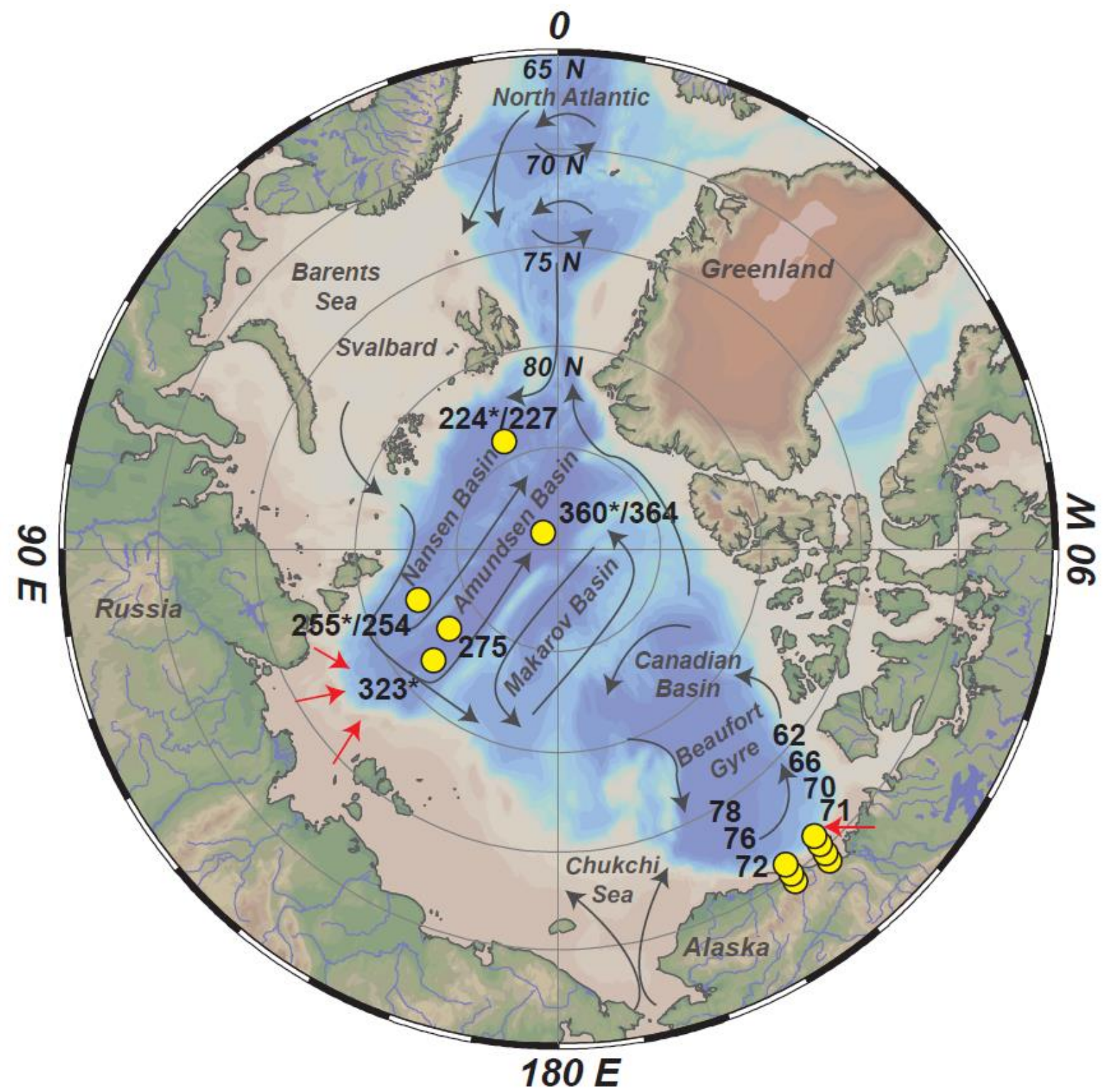


Figure 2. Total PFAS concentration (pg/L), composition $(\%)$ and temperature (T, in ${ }^{\circ} \mathrm{C}$; show in black dots and trends in black line) in water samples from the Arctic Ocean. (Total PFAS concentration is the sum of detectable PFASs; open circle indicates sample below LOQ; zero was assigned for calculating total PFAS when the samples were found below LOQ).
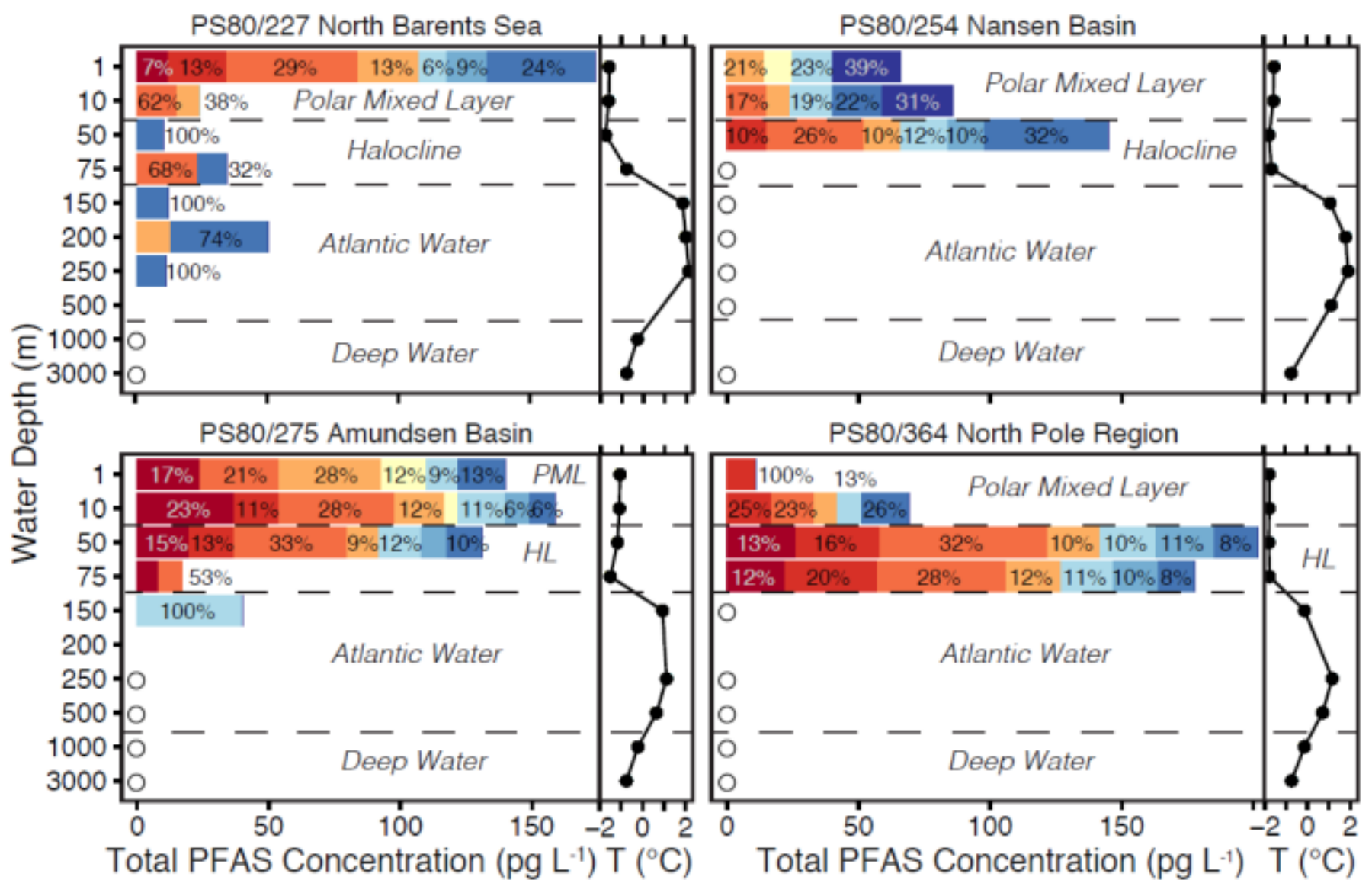

Total PFAS Concentration $\left(\mathrm{pg} \mathrm{L}^{-1}\right) \mathrm{T}\left({ }^{\circ} \mathrm{C}\right) \quad$ Total PFAS Concentration $\left(\mathrm{pg} \mathrm{L}^{-1}\right) \mathrm{T}^{\circ}\left({ }^{\circ} \mathrm{C}\right)$

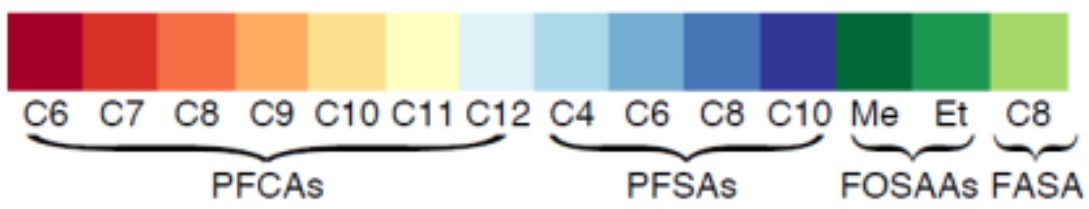


Figure 3. Total PFAS concentration (pg/L) and composition in water samples from the Arctic shelf: (A) transect at $144{ }^{\circ} \mathrm{W}$ longitude; (b) transect at $139^{\circ} \mathrm{W}$ longitude (see Figure 1). (Total PFAS concentration is the sum of detectable PFASs; zero was assigned for calculating total PFAS when the samples were found below LOQ)
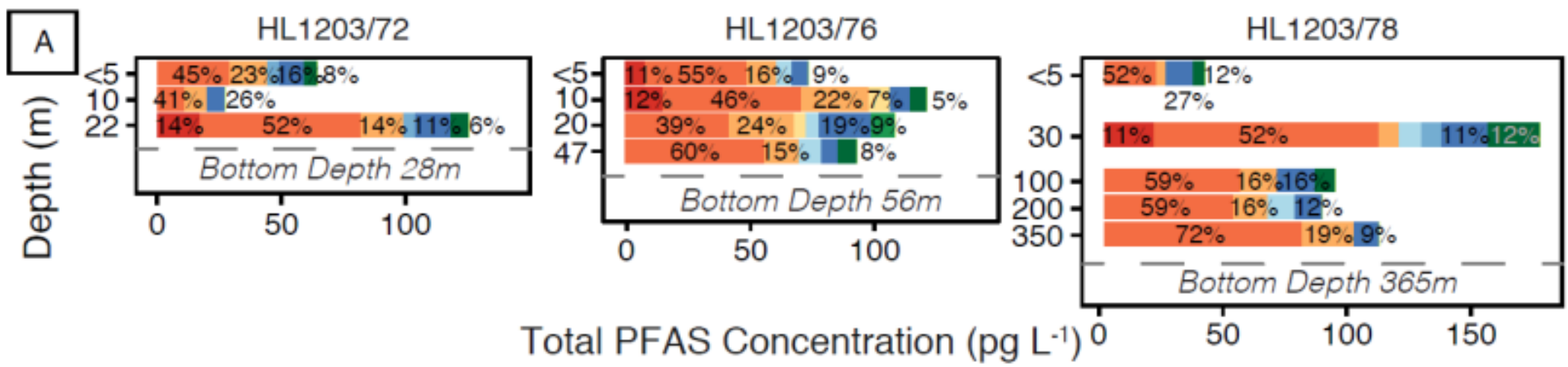

Total PFAS Concentration (pg L-1)
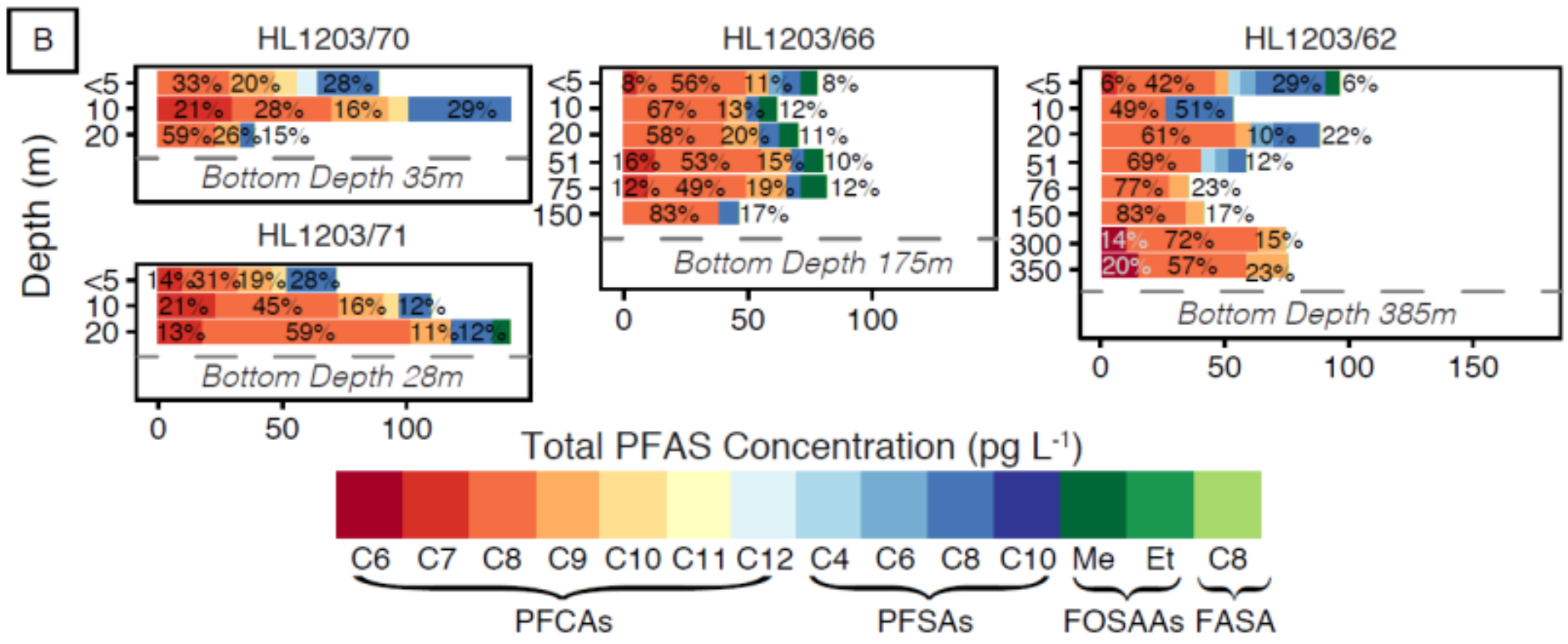
Figure 4. Concentrations and composition of PFAS in snow and meltpond water samples collected from the ice station in the Arctic (see Figure 1 for locations)
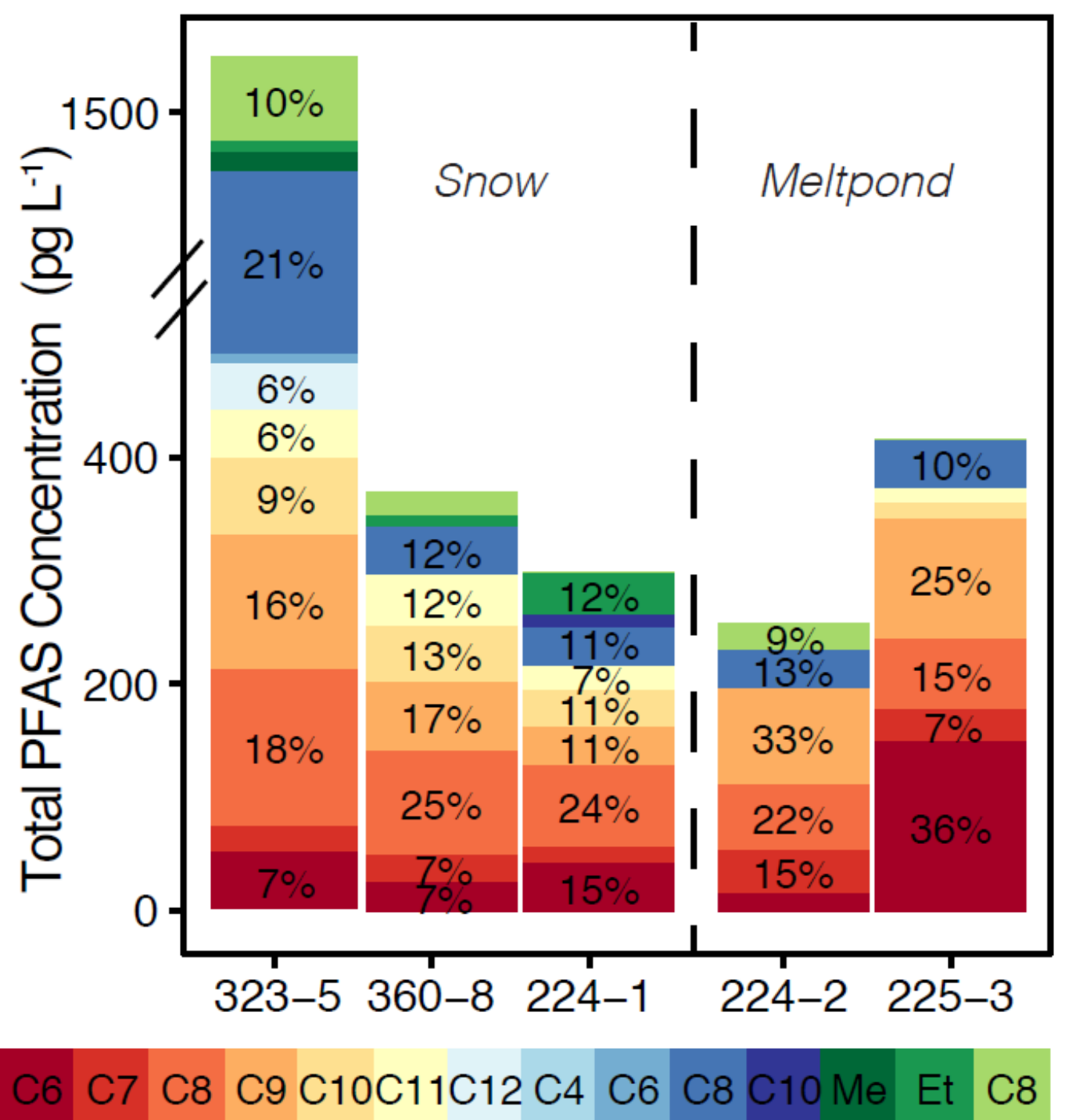

PFCAs

PFSAS FOSAAs FASA 
1 Figure 5. Modeled PFOS and PFOA concentrations in surface waters (PML, 0-20 m), 2 subsurface (including the halocline, 20-200 m), and deep waters (200 m - bottom) of the 3 Arctic Ocean based on the geochemical box model adapted from Soerensen et al. ${ }^{38}$ For PFOS, 4 median and low emissions scenarios represent uncertainty in the magnitude of historic 5 discharges from North American and European wastewater and rivers into the North Atlantic 6 Ocean, that then circulate into the Arctic based on the 3-D ocean simulation of Zhang et al. ${ }^{39}$ 7 For PFOA, resolved oceanic inputs are not available, thus we used deposition rates from the 8 Devon ice cap in the Canadian High Arctic to estimate the contribution of atmospheric inputs 9 to those observed in the polar mixed layer (PML) in this work (bottom panel). Dashed lines 10 represent alternate assumptions for deposition after 2007: the top line assumes deposition values from 2007 continue, and the bottom line assumes zero deposition.

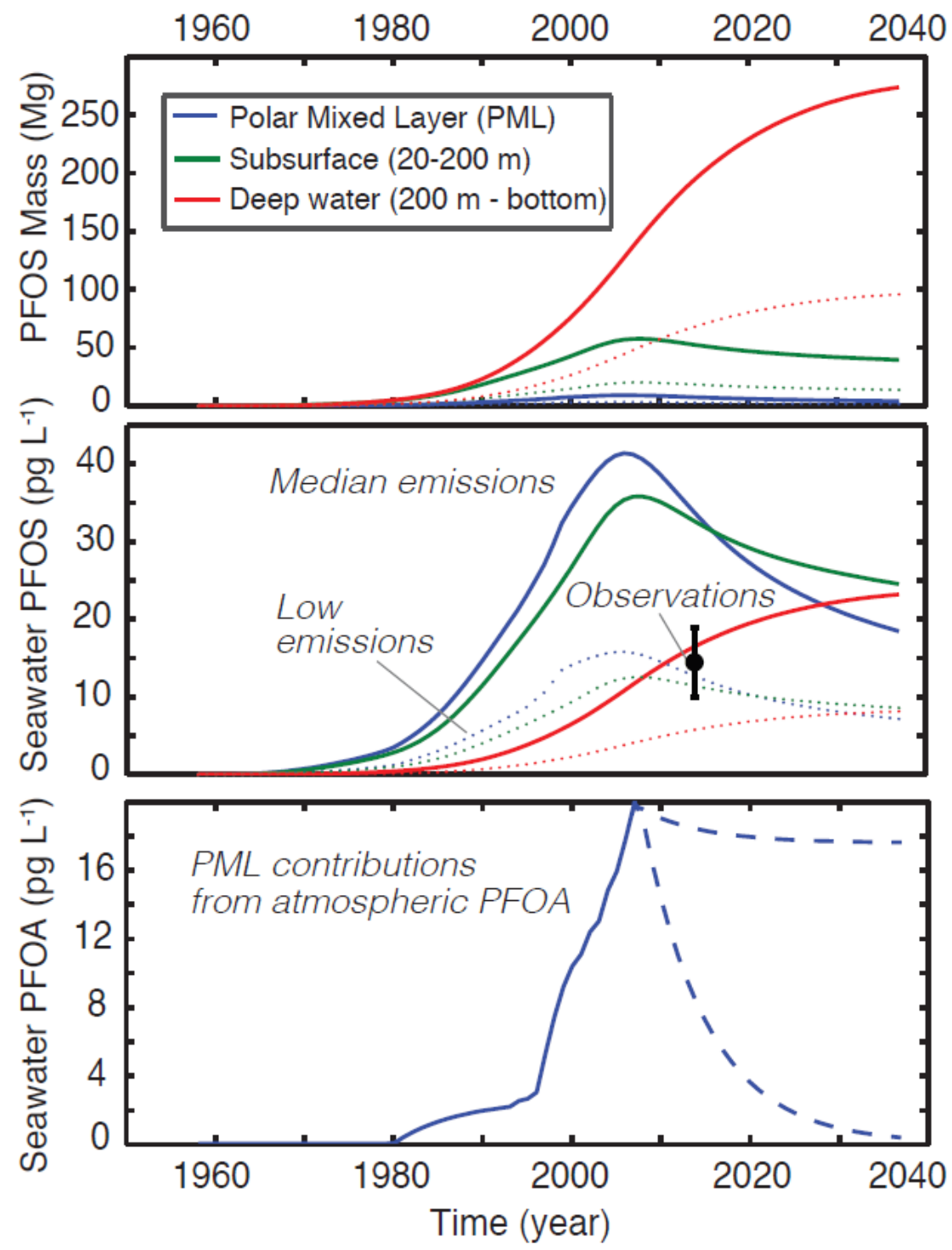

